\title{
RESTAURATIE VAN DRIE CHINESE EXPORTSCHILDERINGEN
}

\section{Inleiding}

In het Rijksmuseum Amsterdam hangen in zaal 1.5 Nederland overzee sinds de heropening in april 2013 drie Chinese exportschilderingen, Gezicht op Kanton, de Rede van Whampoa en Gezicht op Macao (afb. 1). Deze Drie gezichten op de Parelrivier zijn drie schilderingen afkomstig uit de collectie van Jean Theodore Royer (1737-1807) en behoren tot de collectie van Rijksmuseum Volkenkunde (nu onderdeel van het Nationaal Museum van Wereldculturen, NMvW). Dat deze drie schilderingen nu in het Rijksmuseum hangen is het resultaat van een bijzondere, vijf jaar durende samenwerking tussen Rijksmuseum Volkenkunde, het Rijksmuseum Amsterdam (daartoe in staat gesteld door het Irma Theodora Fonds), en twee zelfstandige restauratoren, Pauline Marchand en Nico Lingbeek, met een belangrijke bijdrage in de vooronderzoeken door de Stichting Restauratieateliers Limburg (SRAL) en de Rijksdienst voor het Cultureel Erfgoed (RCE). ${ }^{1}$

In 2008 vroeg het Rijksmuseum Amsterdam de drie schilderingen in bruikleen voor de nieuwe vaste opstelling. De schilderingen verkeerden destijds in heel slechte conditie en het was duidelijk dat veel voorbereidingstijd nodig zou zijn om deze mooie getuigen van een tijd te stabiliseren en weer toonbaar te maken. Dit stuk doet verslag van de belangrijkste aspecten van dit restauratieproject.

\section{Geschiedenis}

Op het moment dat aan de restauraties werd begonnen was er al veel onderzoek gedaan naar de herkomst en geschiedenis van deze voorwerpen. ${ }^{2}$

De drie schilderingen behoren tot een grotere groep Chinese exportschilderingen in het NMvW, die tussen 1770 en 1845 in Kanton (nu Guangzhou) gemaakt zijn.

$\mathrm{Na}$ een ban van bijna 150 jaar op elke vorm van maritieme en internationale activiteit was Kanton de enige haven in China van waaruit handel met Westerse landen was toegestaan. Alle import- en exportartikelen werden hier verhandeld: thee, zijde, porselein, schilderingen en andere kunstvoorwerpen. Britse, Franse, Nederlandse en andere Europese handelscompagnieën richtten kantoren in aan de rand van Kanton, aan de oever van de Parelrivier. Later kwamen hier ook Amerikaanse maatschappijen bij. Naast thee was porselein de primaire handelswaar. Met het transport terug naar Europa van de koopwaar, samen met de handelslieden en hun souvenirs, steeg de interesse in Chinese exportkunst, en afbeeldingen van een dergelijk vreemd en exotisch land werden steeds meer gewild. In Kanton ontstonden gespecialiseerde schildersateliers waar de Westerse handelslieden konden kiezen uit portretten, bloemen- of maritieme sceñes in 2023 09:21:42AM 

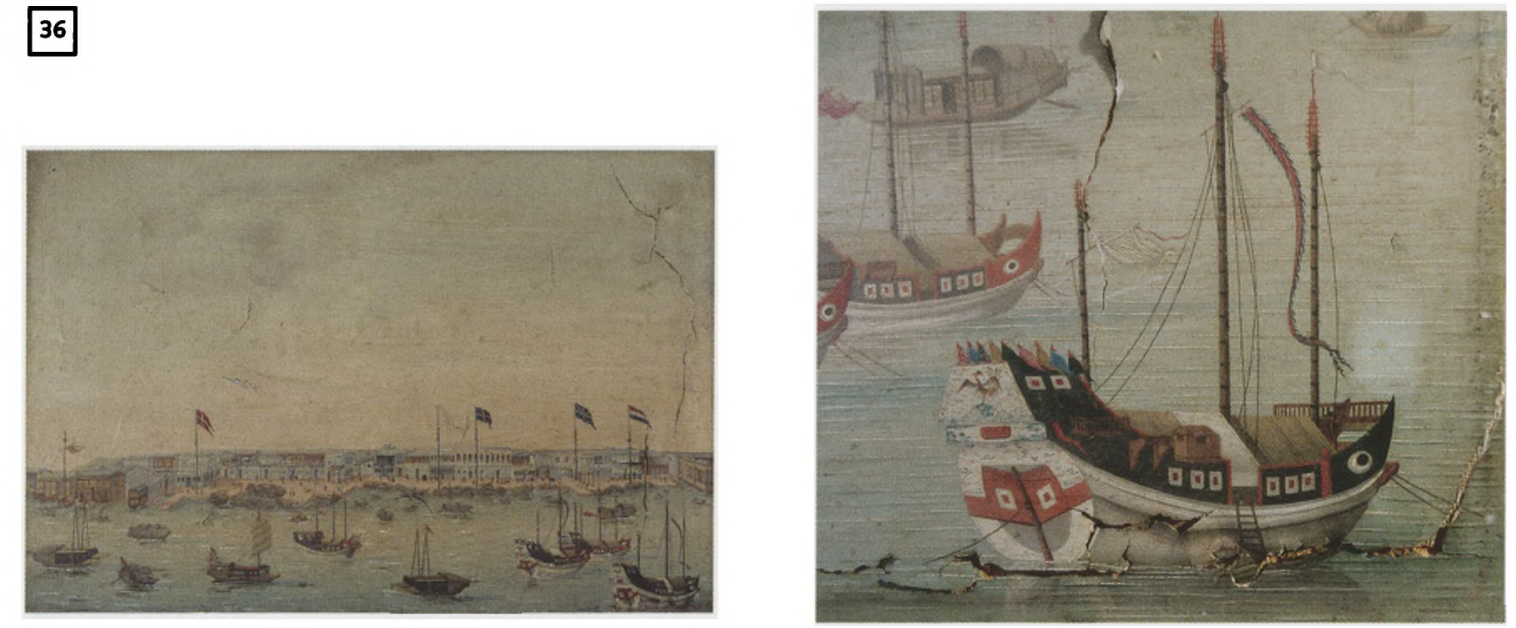

Afb. 2 (links)

De Rede van Kanton voor behandeling (inv. nr. RV 360-338). (Foto: Pauline Marchand)

Afb. 3 Detail van scheur. (Foto: Pauline Marchand) gouache, aquarel of olieverf om mee te nemen op hun reis terug naar huis. Een vaak geziene set verbeeldde de belangrijke locaties voor de handel tussen China en het Westen tussen 1750 en 1842: Kanton, Macao en Whampoa. ${ }^{3}$ De hier besproken drie schilderingen zijn vroege voorbeelden hiervan, geschilderd in $1773 .^{4}$

Een schip met handelswaar uit het Westen meerde in eerste instantie aan in Macao, waar een handelslicentie aangevraagd moest worden. Met de licentie kon het schip doorvaren naar Whampoa, van waaruit de handelswaar op kleinere schepen overgebracht werd naar Kanton. De bemanning van het schip verbleef in Whampoa. In Kanton mochten alleen de handelslieden zelf verblijven gedurende het handelsseizoen van augustus tot januari. De andere helft van het jaar brachten ze vaak in Macao door, waar ook hun gezin verbleef tijdens het handelsseizoen.

\section{Conditie en materiaalonderzoek}

Het NMvW heeft in zijn collectie drie soorten Chinese exportschilderingen: schilderingen achter glas, olieverfschilderingen, en schilderingen op een ondergrond van papier en canvas. De drie, nu getoond in het Rijksmuseum Amsterdam, behoren tot de laatste groep. De afbeeldingen zijn geschilderd op papier waarbij onder het papier canvas zat. Tijdens de behandeling kon worden achterhaald dat het papier eerst op het canvas moet zijn gelijmd alvorens beide op het schilderijraam zijn gezet. Dat werd duidelijk omdat papier en canvas samen in de hoeken om de lijst gevouwen zijn.

De combinatie van papier en canvas heeft tot grote schade aan de schilderingen geleid doordat beide materialen anders op vocht reageren. Grote scheuren, vooral in de twee schilderingen de Rede van Kanton en de Rede van Whampoa, zijn het gevolg van spanningen in vooral het papier dat stugger is dan de canvas, en door de verflaag stijf is geworden (afb. 2 en 3 ). Dat de schilderingen in hun verleden aan vocht zijn bloot gesteld was ook te zien aan een witte laag (blanching) op het oppervlak, vooral in de lagere delen van het beschilderd oppervlak. Het oppervlak van de schilderingen was sterk vervuild met een grijze laag met veel kleine donkere vlekjes. Het leek access 

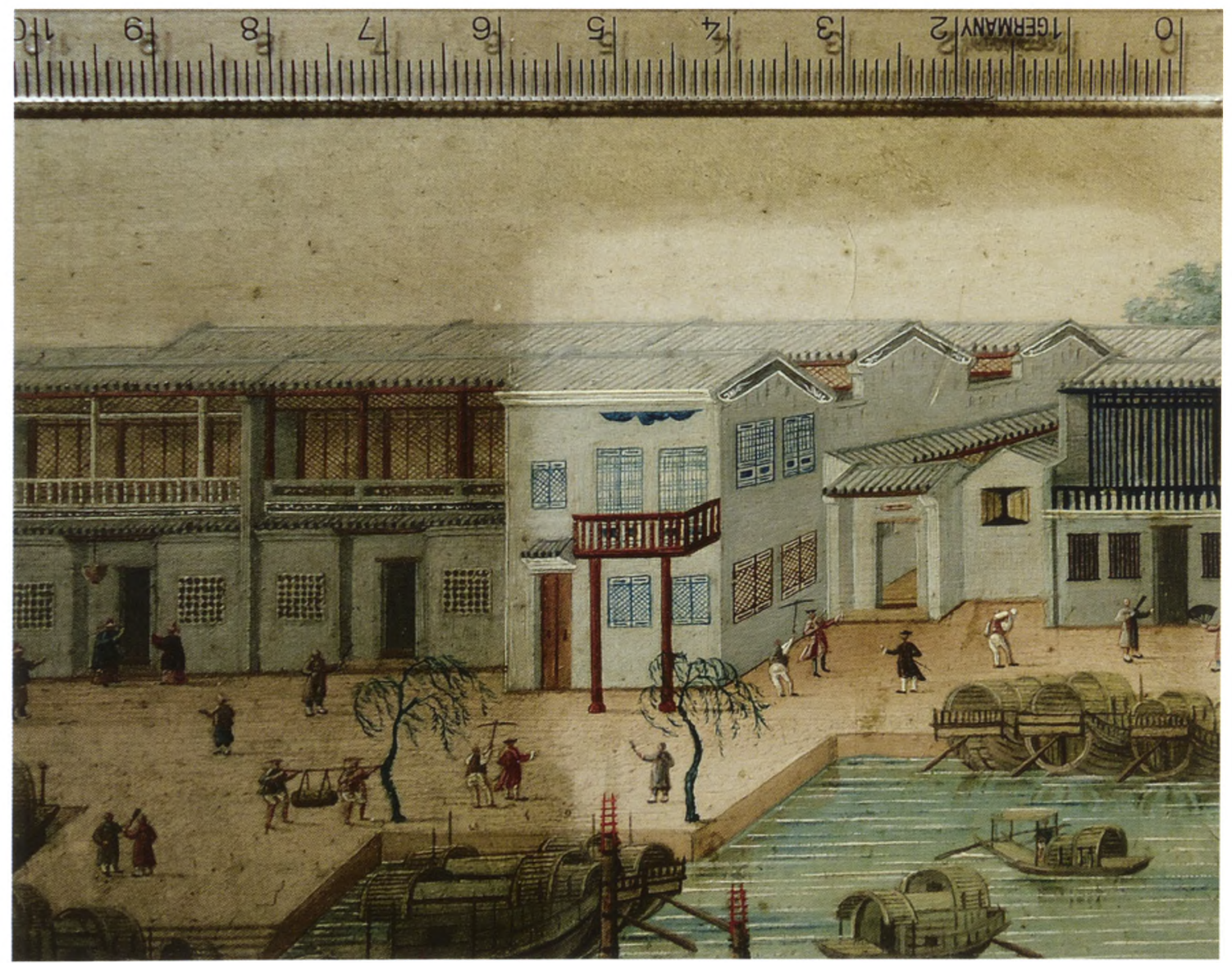

Afb. 4

Detail Rede van Kanton tijdens schoonmaak.

Hierop is de minutieuze schilderstijl te zien en de kleine vlekjes die na schoonmaak overbleven. (Foto: Pauline Marchand) erop dat het oppervlak nooit gevernist is geweest, waardoor het vuil vastgebakken zat, zowel op als ook ín het oppervlak.

De schilderingen leken te zijn geschilderd in een vermenging van Chinese en Europese technieken. Hoewel de afbeeldingen op minutieuze manier geschilderd zijn en het uiterlijk hebben van een matte gouache, zijn ze geschilderd in olieverf. China kende geen traditie in olieverfschildering maar had een lange traditie van waterverf op zijde en papier. Tijdens de Ming-dynastie (1368-1644) werden Europese religieuze etsen, kleine olieverfschilderingen en gedrukte boeken door jezuïtische missionarissen meegebracht naar China, maar deze werden toen vooral met een bepaalde bevreemding bekeken. Hoewel deze af en toe gekopieerd werden, hadden ze alleen een kleine invloed op de Chinese kunst van die tijd. Later, in de $18^{\mathfrak{c}}$ eeuw zijn Westerse schildertechnieken, compositie, gebruik van kleur en perspectief aan het keizerlijke hof geïntroduceerd. Deze 'hybride' werken vonden echter geen waardering buiten de muren van het keizerlijke hof, aangezien dichtkunst en kalligrafie hoger aanzien genoten. De Westerse invloed was vooral terug te vinden in schilderingen gemaakt voor de Westerse markt. ${ }^{5}$

Om een inzicht in de opbouw van de schilderingen te krijgen en bijvoorbeeld uit te zoeken of inderdaad geen vernis is gebruikt, is voorafgaand aan de behandelingen materiaalonderzoek uitgevoerd door de SRAL en het $R_{\mathrm{N}} \mathrm{CE}_{\mathrm{ee}} \mathrm{B}$ access 

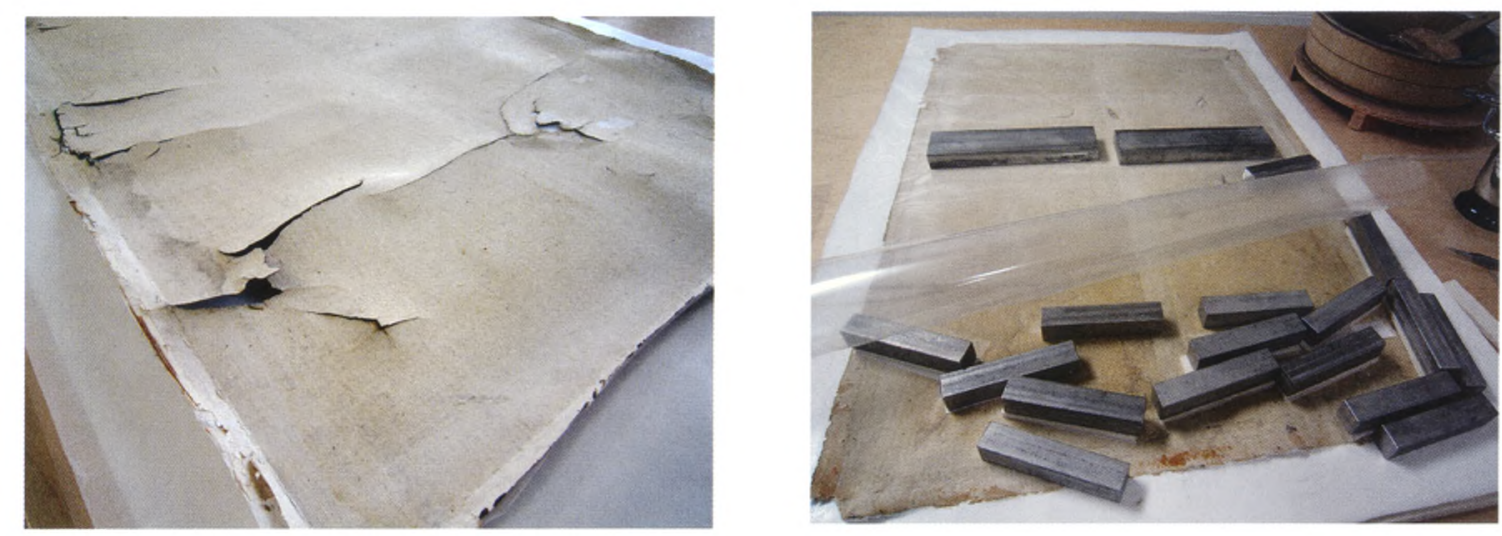

Afb. 5 (links)

Papieren achterkant Rede van Whampoa na loshalen van het doek. (Foto: Nico Lingbeek)

Afb. 6

Achterkant van Rede van Kanton onder bezwaring na bij elkaar brengen van de scheuren. (Foto: Nico Lingbeek)

De uitkomsten gaven een vergelijkbaar beeld weer van de drie objecten. Het papier en canvas werden onderzocht met behulp van een stereomicroscoop met polariserend licht. De optische en morfologische karakteristieken wezen op rijst- of Mitsumatavezels. ${ }^{7}$ De vezels van de canvas bevatten katoenen en dikkere jutevezels. Het aanwezige katoen is waarschijnlijk een belangrijke reden voor de grote spanningen die zijn ontstaan in de lagen van de objecten. Katoen neemt veel vocht op en wordt slap waardoor het papier met de verflaag onder grote spanning komt te staan en barst. De lijm die is gebruikt tussen de canvas en het papier werd geïdentificeerd als voornamelijk stijfsel, met kleinere hoeveelheden proteïne. Dwarsdoorsnedes van de verflagen toonden als onderste laag op het papier een bruine onderlaag, daarop twee (en op sommige plaatsen drie) te onderscheiden gronderingslagen en één bovenlaag. Er was op geen van de monsters een vernis aanwezig. Het bindmiddel bevatte lijnzaadolie, in een van de monsters werden sporen van paraffine gevonden. Door elektronenmicroscopisch onderzoek konden de pigmenten bepaald worden: loodwit en kalk in de grondering; en loodwit, Pruisisch blauw en auripigment in de verflagen.

\section{Behandeling ${ }^{8}$}

De voornaamste uitdaging in de behandeling van deze voorwerpen was de stabilisering, het planeren (effenen) en het sluiten van de scheuren in het beschilderde papier en het verwijderen van het vuil. De combinatie van de materialen, olieverflaag op papier en canvas, maakte de samenwerking met zowel een schilderijen- als ook een papierrestaurator wenselijk. Verwijdering van het vuil, vullen van lacunes en het retoucheren van vullingen werden uitgevoerd door de schilderijenrestaurator. Ook was het voor haar mogelijk om de kleine scheuren in een van de schilderingen bij elkaar te brengen. Bij dit object (Gezicht op Macao) waren alleen twee kleine scheurtjes te vinden waarbij vanuit de voorkant van de schildering gewerkt kon worden om de scheuren licht te bevochtigen, vlakker te maken en te sluiten. Hierbij was de input van de papierrestaurator niet vereist. Het verwijderen van het vuil bleek een langdurig proces omdat het vuil in de bovenste verflaag ingebakken was, veroorzaakt door het ontbreken van de vernis. Veel verschillende oplosmiddelen werden getest voordat met tri-ammoniumcitraat een bevredigend resultaat bereikt kon worden. Echter bleven ook hier enkele vlekken over (afb. 4). 
Bij de andere twee schilderingen was de input van een papierrestaurator gewenst. Hier waren de scheuren in de papier/verflaag zo groot en was de vervorming rond de scheuren zo sterk dat duidelijk was dat deze alleen vlakker gemaakt konden worden door het beschilderde papier los te halen van het onderliggende doek. Om zo veel mogelijk van de opbouw en de integriteit van deze twee objecten te bewaren was de eis dat het doek bij het verwijderen op de lijst kon blijven zitten zodat zowel papier als doek zo min mogelijk beschadigd raakten. Gelukkig was de oude lijm tussen de twee lagen zo bros geworden dat met een spatel de twee lagen mechanisch van elkaar gescheiden konden worden (afb. 5). Het papier werd ondersteboven bevochtigd in een langzaam proces tussen lagen van filtreerpapier en isolerende lagen. Op deze manier kon het papier langs de scheuren zacht gemaakt worden, worden neergelegd en met Japans papier aan elkaar worden gehecht om het onder gewicht te laten drogen (afb. 6). Vervolgens is de achterkant met meerdere lagen Japans papier gedoubleerd. De randen van de doublering zijn daarbij over een houten frame gelijmd waardoor het geheel onder lichte spanning kon drogen en de papier/verflaag verder glad kon trekken. De gedroogde en gedoubleerde papierlaag werd vervolgens weer teruggeplaatst op het doek. Na het sluiten van de scheuren en het vlakken van deze twee schilderingen kon de schilderijenrestaurator de laatste gebieden rond de barsten schoonmaken, die voorheen, toen deze nog omhoog stonden, te kwetsbaar waren voor aanraking.

Het was duidelijk dat een belangrijk historisch aspect van deze schilderijen was dat deze niet gevernist waren en het was daarom ook zeker niet de bedoeling nu een vernis op te brengen. Dat betekent echter dat het oppervlak gevoelig zal blijven voor vuil maar ook voor aanraking en eventuele schommelingen in het klimaat in de zalen van het Rijksmuseum. Het tonen in een gesloten vitrine werd overwogen, maar het was duidelijk dat hierdoor de waardering van de objecten zou verminderen. Conservator Jan van Campen beoogde de objecten te tonen zoals deze vermoedelijk als set in een woonhuis aan het eind van de $18^{\mathrm{e}}$ eeuw aan de muur hadden gehangen (afb. 7). Daarom is ervoor gekozen de lijsten te voorzien van een glas in de lijst dat met een toegevoegde achterkant van karton een geseald pakket kon vormen

Afb. 7

De drie schilderijen op zaal in het Rijksmuseum.

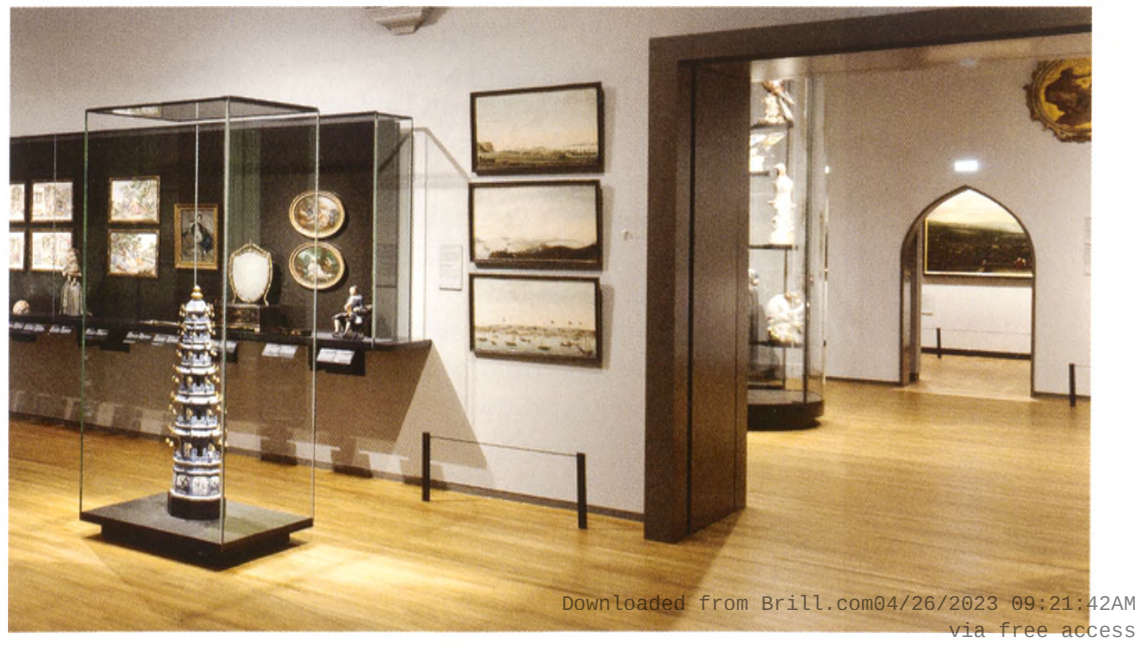


dat veranderingen van de luchtvochtigheid, maar ook nieuwsgierige vingers van het publiek op afstand kan houden. Het inlijsten werd gedaan in de papier- en lijstenrestauratieafdelingen van het Rijksmuseum.

\section{Samenwerking}

Tijdens het hele traject van vooronderzoek en de keuzes van behandelingen is nauw overleg geweest tussen alle partijen. Het interdisciplinaire karakter van dit project maakte het mogelijk de expertise van professionals uit verschillende disciplines bij elkaar te brengen. Dit leidde tot veel verrijkende discussies en heeft geresulteerd in veel nieuwe kennis over deze bijzondere groep van objecten.

- Margrit Reuss is opgeleid tot restaurator van archeologische, kunstnijverheid en volkenkundige objecten aan de Staatliche Akademie der Bildenden Künste in Stuttgart. Zij werkt sinds 2000 voor Rijksmuseum Volkenkunde/Nationaal Museum van Wereldculturen $(\mathrm{NMvW})$.

\section{Literatuur}

Paul A. Van Dyke en Maria Kar-wing Mok, Dating the Canton Factories 1760-1822, publication forthcoming.

René Hoppenbrouwers, Pauline Marchand, Kate Seymour en Qui Xiaohui, Three China Trading Paintings from the National Museum of Ethnology, ongepubliceerde onderzoeksdocumentatie, Stichting Restauratie Ateliers Limburg (SRAL).

Rosalien van der Poel, Twenty export oil paintings from China in the collection of the National Museum of Ethnology: A closer examination, Universiteit Leiden (Stagerapport 2006-2007).

Rosalien van der Poel, Rijk Palet: Chinese Exportschilderkunst overzee, doctoraalscriptie Universiteit Leiden (2008).

Rosalien van der Poel, 'China Back in the Frame: An Early Set of Three Chinese Harbour Views in the Rijksmuseum', in: Rijksmuseum Bulletin 61 (2013): pp. 277-93.

Margrit Reuss, Pauline Marchand en Nico Lingbeek, 'Made in China': techniques when approaching the conservation of three China trade paintings', in: Journal of the Institute of Conservation, 37:2 (2014): pp. 120-35.

\section{Noten}

1. Met dank aan Jan van Campen en Dionysia Christoforou (Rijksmuseum), René Hoppenbrouwer (SRAL), Henk van Keulen (RCE), Bas van Velzen (UvA).

De restauratie werd uitgevoerd door Pauline Marchand Schilderijenrestaurator in Rotterdam, en Nico Lingbeek Papierrestauratie Haarlem.

2. Van der Poel 2006 en Van der Poel 2008. Een uitgebreid overzicht van de geschiedenis van deze drie voorwerpen is te vinden in Van der Poel 2013.

3. Soms kende men ook een vierde deel: Bocca Tigris, de nauwe passage in de Parelrivier tussen Macao en Kanton.

4. Archiefonderzoek kon deze schildering van de rede van Kanton aan de hand van de bouw van de handelskantoren dateren in 1773. Zie Van Dyke and Mok, forthcoming.

5. Van der Poel 2008.

6. Hoppenbrouwers et al. 2009.

7. Vezelherkenning aangevuld door Bas van Velzen, Universiteit van Amsterdam.

8. Een gedetailleerde beschrijving van de behandeling is te vinden in Reuss et al. 2014. 